\title{
Less Government-More Wealth? On the Macroeconomics of a Smaller Public Sector in Europe
}

\author{
GOTTFRIED HABER*, REINHARD NECK*, AND WARWICK J. MCKIBBIN**
}

\begin{abstract}
In this paper, we analyze the reactions of European economies to a fiscal policy strategy aiming at diminishing the public sector. Within the framework of the MSG3 model, a macroeconomic model of the world economy, we perform several simulation experiments to explore the effects of reducing government expenditures permanently in different phases of the business cycle. For this purpose, we combine the fiscal contraction with negative and positive, Euro Area-wide and global, supply and demand shocks. It turns out that adverse Keynesian effects on output and employment tend to be mostly weak and short-lived, whereas long-run effects on output and employment are favorable. Due to these long-run effects, the fiscal contraction policy raises welfare as measured by an asymmetric quadratic objective function. The size of these welfare effects depends on the initial situation in a non-trivial manner. (JEL E6, H1, H3, H6)
\end{abstract}

\section{Introduction}

The recent debate about the Stability and Growth Pact of the European Union [Allsopp and Artis, 2003; Allsopp and Vines, 1998; Buti and Sapir, 1998, 2003; De Grauwe, 2003; Eijffinger and de Haan, 2000; Hughes Hallett and Mooslechner, 1999; Neck, 2002; Neck and Holzmann, 2002] has revealed highly divergent opinions about the virtues and vices of consolidating government budgets and reducing public debt among EU policy-makers, the public and economists. In particular, both short-run and long-run effects of balancing budgets, the appropriate time schedule and the methods to achieve this goal are highly controversial. For example, it is not clear whether reducing government expenditures or raising taxes will be preferable, and arguments are put forward both for a 'shock therapy' (quick consolidation) and for a more gradual strategy. A crucial question to be answered before informed decisions about a framework for budgetary policies in Europe can be made is how to evaluate a reduction of the size of the public sector. If a diminished public sector results in a less stable macroeconomic environment, then tax increases may be the only possibility to achieve balanced budgets.

\footnotetext{
*University of Klagenfurt-Austria, **Australian National University-Australia and The Brookings Institution-U.S.A. Financial support from the Jubiläumsfonds of the Austrian National Bank (project no. 9152) and from the Ludwig Boltzmann Institute for Economic Analyses is gratefully acknowledged. The views expressed in this paper need not be those of the Austrian National Bank. Thanks are due to Harald Stieber for helpful comments.
} 
On the other hand, if a diminished public sector does not have such effects or even improves upon the performance of the economies affected, cutting down government expenditures will be the preferred strategy for European fiscal policy-makers. Improved knowledge on this issue will also be of utmost importance for possible further revisions of the EU Stability and Growth Pact.

In this paper, we explore possible consequences of diminishing the public sector by reducing government expenditures in several EU countries. The analysis is conducted within the framework of the MSG3 macroeconomic model of the world economy, a twosector version of the G-Cubed model of McKibbin and Wilcoxen [1998], which is descended from the McKibbin and Sachs [1991] MSG2 model. In the version of the model used, several EMU member countries, the UK, the CEEC, the U.S.A., and Japan are modeled in a detailed way, as are blocks of the other EU countries and of other countries. We study the effects of permanent reductions of government expenditures, starting either from baseline simulations of the model ('business as usual', i.e., projections of future time paths assuming no exogenous shocks) or from simulations assuming adverse/ favorable supply shocks (fall/rise of total factor productivity) or negative/positive demand shocks (fall/rise of autonomous consumption). For the European Central Bank (ECB), we assume monetary policy following the rule of inflation targeting. In all simulations, the intertemporal government budget constraint is fulfilled. The results show that diminishing the public sector permanently has (relatively weak) adverse short-run effects on output and employment but raises output in the long run. The time pattern of the adjustment of the economies determines the overall welfare effects of reducing government expenditures.

\section{The MSG3 Model}

For the calculations in this paper, the MSG3 model, a dynamic, intertemporal, general-equilibrium model of a multi-region world economy, is applied. Based upon microeconomic foundations by assuming that economic agents maximize intertemporal objective functions, the model exhibits a mixture of classical and Keynesian properties: Partly rational expectations in combination with various rigidities allow for deviations from fully optimizing behavior. In particular, nominal wages are assumed to adjust slowly in most of the industrial economies. Nevertheless, the model solves for a full intertemporal equilibrium in which agents have rational expectations of future variables. As a model with theoretically constrained long-run properties, it can display how the short-run adjustment of the world economy to exogenous shocks depends upon the longrun outcome.

The MSG3 model is a two-sector version of the twelve-sector G-Cubed multi-country model of McKibbin and Wilcoxen [1998]. In many ways, the aggregation gives a model similar to the McKibbin and Sachs [1991] MSG2 model, except that there is substantial estimation of key parameters in the MSG3 model. The two sectors of production are energy and non-energy. There is also a third capital goods producing sector. MSG3 is, therefore, very similar in sectoral and country coverage to the MSG2 model but includes many of the features of the newer G-Cubed model. Overall, the model is designed to provide a bridge between computable general equilibrium models and macroeconomic models by integrating the more desirable features of both approaches. Details on this integration and how the G-cubed bridges the gap between CGE and traditional macroeconometric models can be found in McKibbin and Wilcoxen [1998]. Additional resources are available on the web (http://www.msgpl.com.au/). 
The main features of the new MSG3 model relative to the MSG2 model are:

1. A better mapping of the energy flows in the economy based on country specific input-output data from the G-Cubed database.

2. Estimated production technologies based on the G-Cubed 12-sector aggregation are aggregated to the two-sector level, which gives a better depiction of the aggregate production substitution possibilities than in the MSG2 model which assumed a Cobb-Douglas specification.

3. Explicit treatment of capital goods in the household and firm sectors. Because the MSG3 model is based on G-Cubed, we also have two additional sectors which create capital goods for investment by firms and capital goods for investment by households. This structural depiction of economies enables a closer examination of the impact of computers and other capital goods investment on overall economic activity globally.

4. There are no residual country blocks in the MSG3 model but detailed structural models for all regions captured by the model.

The MSG3 model has been constructed to contribute to the current policy debate on macroeconomic policy design in different economies. It is a world model with substantial regional disaggregation and some sectoral detail. In addition, countries and regions are linked both temporally and intertemporally through trade and financial markets. Like the MSG2 and G-Cubed models, the MSG3 model contains a strong foundation for analysis of both short run macroeconomic policy analysis as well as long run growth consideration of alternative macroeconomic policies. Intertemporal budget constraints on households, governments, and nations (the latter through accumulations of foreign debt) are imposed. To accommodate these constraints, forward-looking behavior is incorporated in consumption and investment decisions.

The long run of the world economy is driven by a neoclassical growth model, with exogenous technical progress and population growth. Keynesian rigidities in the goods and labor markets in the short run and optimal decisions, conditional on expected future paths of the world economy, drive the short run of the model. Thus, the model captures long-run effects of shocks and short-run dynamics towards these long-run outcomes based on historical experience, with expectations formation providing a link between the long-run outcome and the short-run adjustment.

As the MSG3 model is a fully specified dynamic general-equilibrium model, it incorporates both the demand and the supply sides of the major industrial economies. Stock-flow relations are carefully observed, and intertemporal budget constraints are imposed. Asset prices are determined by intertemporal arbitrage conditions and rational expectations. For the long-run behavior of the model, stock equilibrium, rather than flow equilibrium, is important. Asset prices stabilize in real terms once the desired ratios of asset stocks to GDP are reached. The short run of the model behaves similarly as the basic Mundell-Fleming model under flexible exchange rates and high capital mobility; however, the future paths of the world economy are important in the short run because of the forward-looking behavior in asset and goods markets. The assumptions of rational expectations in financial markets and of partially forward-looking behavior in real spending decisions allow for the incorporation of the effects of anticipated policy changes.

The supply side of the model is specified in an internally consistent manner. Factor input decisions are based in part on intertemporal profit maximization by firms. Labor and intermediate inputs are determined to maximize short-run profits, given a stock of capital that is fixed within each period and adjusted according to a Tobin's q-model of 
investment, where Tobin's q evolves according to a rational-expectations forecast of future after-tax profitability.

The version of the MSG3 model used in this paper, called MSG3v54o, consists of models of the following countries and regions: The United States, Japan, Canada, Australia, the United Kingdom, Germany, France, Italy, Austria, the rest of the Euro Area (REA), the rest of the OECD (ROECD), China, Central and Eastern European economies (CEEC), non-oil developing countries, oil-exporting countries, and Russia. Although the basic theoretical structure for all industrial regions is the same, institutional differences are taken into account, especially in modeling labor markets.

The MSG3 model was fitted to empirical data by a mix of calibration techniques for CGE models and econometric time-series estimates. Behavioral parameters taken from econometric studies and data for macro aggregates were combined with steady-state relations in the model to generate other data. The reference year, for which actual data are replicated, is regarded as representing a point on the stable adjustment path towards the steady state of the model; hence, not all steady-state relations are assumed to hold for that year. The model is solved in linearized form around the base year of 2002 .

\section{Methodology and Simulation Scenarios}

The main task in this paper is to study the consequences of and to assess the welfare effects originating from reducing the public sector in the Euro Area (EA) in the presence of different shock scenarios. This serves to shed light on the advantages and disadvantages of fiscal policies designed to diminish the government sector in recession versus in boom periods. Such policies have been explicitly announced by several European policy-makers, or they might be by-products of efforts aiming at consolidating government budgets without having to raise taxes. In order to analyze such policies, several simulation runs with the MSG3 model are carried out; we focus on European macroeconomic policies, while the other countries and country blocks in the model are assumed not to change their economic policies as reactions to macroeconomic shocks.

With respect to European policies, we assume the following setup: Monetary policy of the ECB follows the strategy of inflation targeting by adjusting the European (i.e., the EA's) money supply. This amounts to the well-known case of one target variable being controlled by one instrument variable; hence the average European inflation rate can be maintained at the baseline values of the model. This results in nearly the same low inflation rate in all countries of the EA (in the model: Germany, France, Italy, Austria, and REA) due to the close linkages between European financial markets. Minor divergence of the regional inflation rates can still be observed, but in negligible magnitudes.

In order to compare the outcomes of different fiscal policies, which are the focus of this paper, an assessment of the results in terms of welfare gains or losses for each of the simulations of supply and demand shocks and fiscal policy setups is required. For this purpose, we define an overall objective function as the sum of the respective welfare loss functions of the EA countries/regions (assuming equal weights for each EA country/ region and neglecting the 'welfare loss' of the ECB). The values of this function are calculated for each scenario, given a specific shock and under different assumptions regarding the economic conditions. Since the objective function is specified as a welfare loss function, lower values represent better results in terms of welfare.

The objective function of each EA country/region is specified as an asymmetric quadratic function that includes the following macroeconomic variables of the respective country/region: The rate of CPI inflation (although, due to inflation targeting by the 
TABLE 1

Variables in the Objective Function (Welfare Loss Function)

\begin{tabular}{llcc}
\hline \hline & $\begin{array}{l}\text { Functional } \\
\text { specification }\end{array}$ & $\begin{array}{c}\text { Exceeding the reference } \\
\text { values affects the } \\
\text { objective function... }\end{array}$ & $\begin{array}{c}\text { Lower values than } \\
\text { the reference values } \\
\text { mean... }\end{array}$ \\
\hline Inflation & Symmetric & - & - \\
Employment & Asymmetric & + & - \\
Real GDP & Asymmetric & + & - \\
Fiscal deficit & Asymmetric & - & + \\
\hline
\end{tabular}

ECB, being close to baseline), employment, real GDP, and the fiscal surplus. Deviations of these target variables from their reference values are the arguments of the quadratic objective functions, but (with the exception of inflation) these deviations are evaluated in an asymmetric way: While overshooting of reference values is punished, undershooting is rewarded. See Table 1 for details.

The reference values in the objective function are the respective baseline values of the model without any shocks. This makes sense, as the baseline represents a stable adjustment path towards the long-run equilibrium of the model. The inflation objective is defined symmetrically, thus, assigning penalties for deviations in both directions because deflation can be regarded as no less of an evil than inflation (see the recent Japanese case of sustained deflation and the related economic problems). On the other hand, we depart from the traditional symmetric objective function of the theory of economic policy because we take into account the long-run effects of macroeconomic policies, which may result, for example, in a permanently higher output. It would not make sense to evaluate such an outcome in a negative instead of a positive way.

In order to assess the effects of fiscal policies aiming at diminishing the size of the public sector at different positions of the business cycle, we consider several shock scenarios, apart from an isolated fiscal policy scenario without any other macroeconomic shocks. In particular, we calculate the effects of a temporary negative supply (total productivity) shock and of a temporary negative demand (autonomous consumption) shock. These shocks are assumed to be global, affecting all regions in the model, or affecting the EA countries/regions only. See Table 2 for a systematic overview of these shocks and the terminology applied.

A negative supply or productivity shock can be interpreted as a temporary inward shift of the production possibility frontiers of the countries affected. Total factor productivity is assumed to fall by 1 percent in the first year, 0.75 percent in the second year, 0.5 percent in the third year, and 0.25 percent in the fourth year as compared to the baseline of the model. A negative demand shock shifts the aggregate demand curve to the left. Here, we simulate the consequences of a temporary exogenous decrease of real private consumption. In these simulations, the autonomous component of real private

TABLE 2

Shock Scenarios

\begin{tabular}{lllc}
\hline \hline & Scope of the shock & EA & World \\
\hline Type of the shock & Supply (productivity) & YO & YX \\
& Demand (consumption) & CO & CX \\
\hline
\end{tabular}


consumption is assumed to fall by 2 percent in the first year, 1.5 percent in the second, 1 percent in the third, and 0.5 percent in the fourth year as compared to the baseline of the model.

In addition, positive supply and demand shocks are simulated; here the same absolute values of change variables are assumed, but with a positive sign. Note that the results of the corresponding negative and positive shock scenarios will only differ with respect to the signs, as the model is locally linearized during the solution procedure. Negative and positive supply and demand shock scenarios can be regarded as representing frameworks of recession and boom, respectively, at the start of the fiscal policy actions, whereas the pure fiscal policy scenarios represent an intermediate position of the business cycle at the fiscal policy action start.

The fiscal policy action under consideration is modeled as a reduction of autonomous government expenditures for goods and services by 0.25 percent of GDP in the first period, followed by $0.5,0.75$, and 1 percent decreases subsequently. The 1 percent of GDP reduction of public expenditure is assumed to be permanent, which in the model means that it is maintained for all periods of the time horizon (96 periods for convergence purposes according to the terminal conditions of the model). For the calculation of the welfare loss function, only the first 20 periods are taken into account, as the discount rate is set at 10 percent, and developments after period 20 do not contribute to the values of the objective function in a significant way.

The long-run reduction of government expenditures by 1 percent of GDP means approximately a reduction by 2 percent of total government expenditures or a reduction by 4 percent of government consumption, given a level of 50 percent of GDP for the former and of 25 percent of GDP for the latter. Similar values have been formulated as targets by, for instance, the present Austrian government. Moreover, it should be noted that this goal is also consistent with fiscal consolidation in the present European situation where several countries exhibit higher fiscal deficits than the 3 percent of GDP reference value set by the Stability and Growth Pact (SGP) and higher stocks of public debt than 60 percent of GDP (also set by the SGP). In order to decrease these debt values, getting rid of the excessive deficits will not suffice but surpluses of the public finances have to be achieved in the long run. Given the present problems of several (major) countries with the 3 percent of GDP limit for the fiscal deficit, our assumptions about government expenditure reduction seem to be rather moderate.

\section{Temporary Demand and Supply Shocks}

In the first step, we analyze the effects of the negative and positive temporary demand and supply shocks affecting the EA countries/regions, which represent a framework of recession and boom, respectively, for the European fiscal policies diminishing the public sector. Here we assume no fiscal policy shock (or the continuation of fiscal policies from the baseline) for the EA countries/regions in order to define benchmarks for the scenarios with active fiscal policies.

\section{Negative Supply Shock}

A negative supply shock causes the well-known stagflation dilemma in the short run: GDP decreases while the price level increases. Dealing with this type of shock is nontrivial, as expansionary policy measures would also increase inflation, while restrictive economic policy would further reduce real output. Considering a negative supply shock, the results in the MSG3 model are as follows: During the shock there is a short-run 
inflation pressure, which is stabilized by the ECB by cutting money supply. This results in nearly zero inflation rates (with active monetary policy) for all EA countries, but increases output losses far beyond the maximum decrease in total factor productivity of 1 percent to approximately 2 percent in the first period. Nominal interest rates are increased by more than 2 percentage points in the first year of the shock, but return to the baseline rather quickly. As expected, employment is also reduced at the beginning of the shock (by up to nearly 2 percent) and returns to the long-run equilibrium values after 10 periods. The fiscal deficit increases due to the reduction in output and, thus, in taxes; after about 10 periods, the deficit returns to the baseline. As the shock is temporary, the long-run values of all variables are the same as in the baseline solution. Figure 1 shows the deviations of some key variables from their baseline values for this
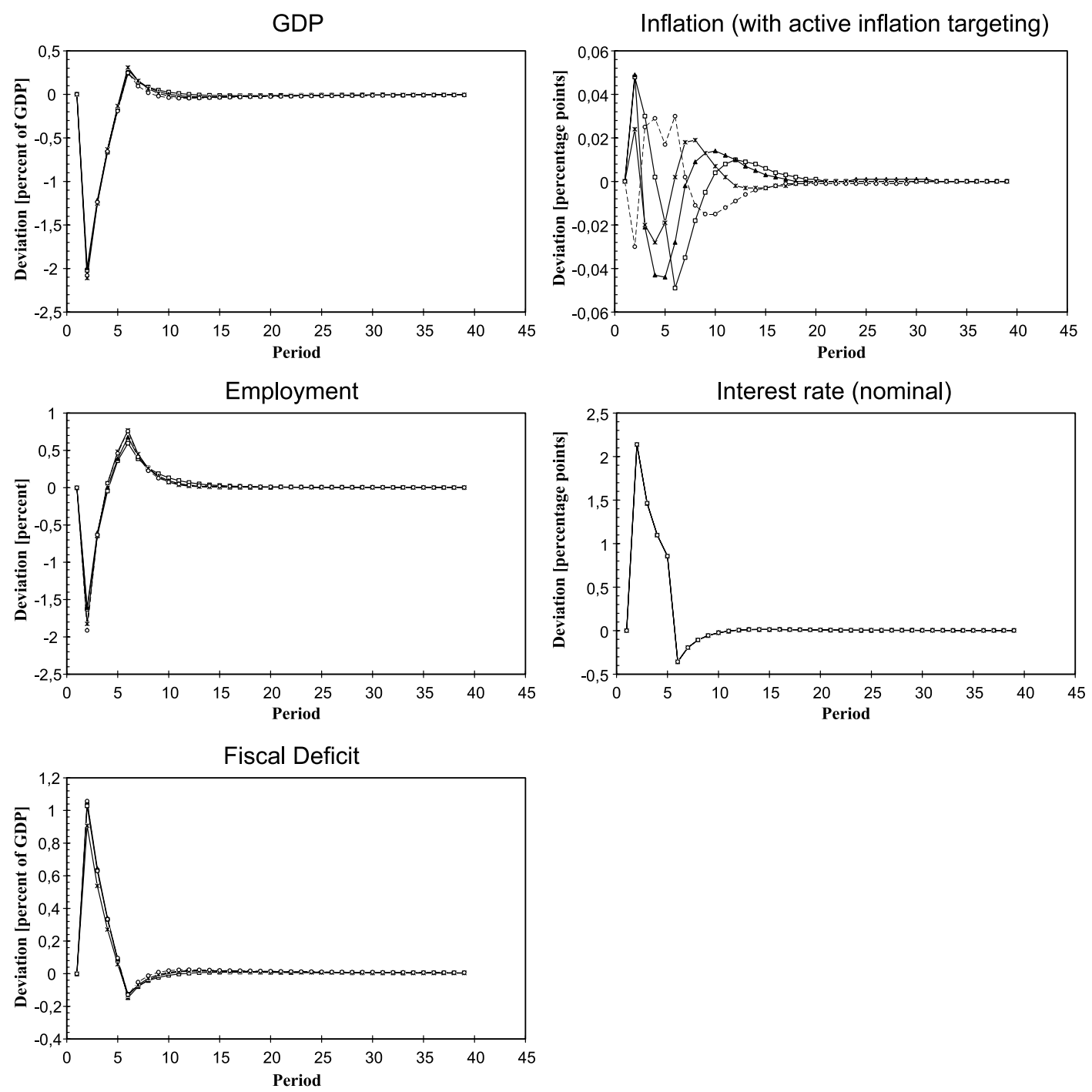

FIGURE 1. Temporary Negative Supply Shock. Germany: square; Austria: triangle; France: asterisk; Italy: circle. 
shock. The results for a global shock of the same magnitude are qualitatively the same as for the shock affecting the EA countries only but slightly stronger.

\section{Negative Demand Shock}

A negative demand shock does not raise the stagflation problem described above, as the price level faces downward pressure in this case. Figure 2 shows the simulation results of this scenario for a demand shock affecting the EA countries/regions. The negative demand shock results in disinflation impulses together with a drop in aggregate demand if the ECB does not counteract these tendencies by responding with expansionary monetary policies. If the ECB intervenes, as is assumed here, nominal interest rates are cut down by up to 2 percentage points. This reaction of the ECB more
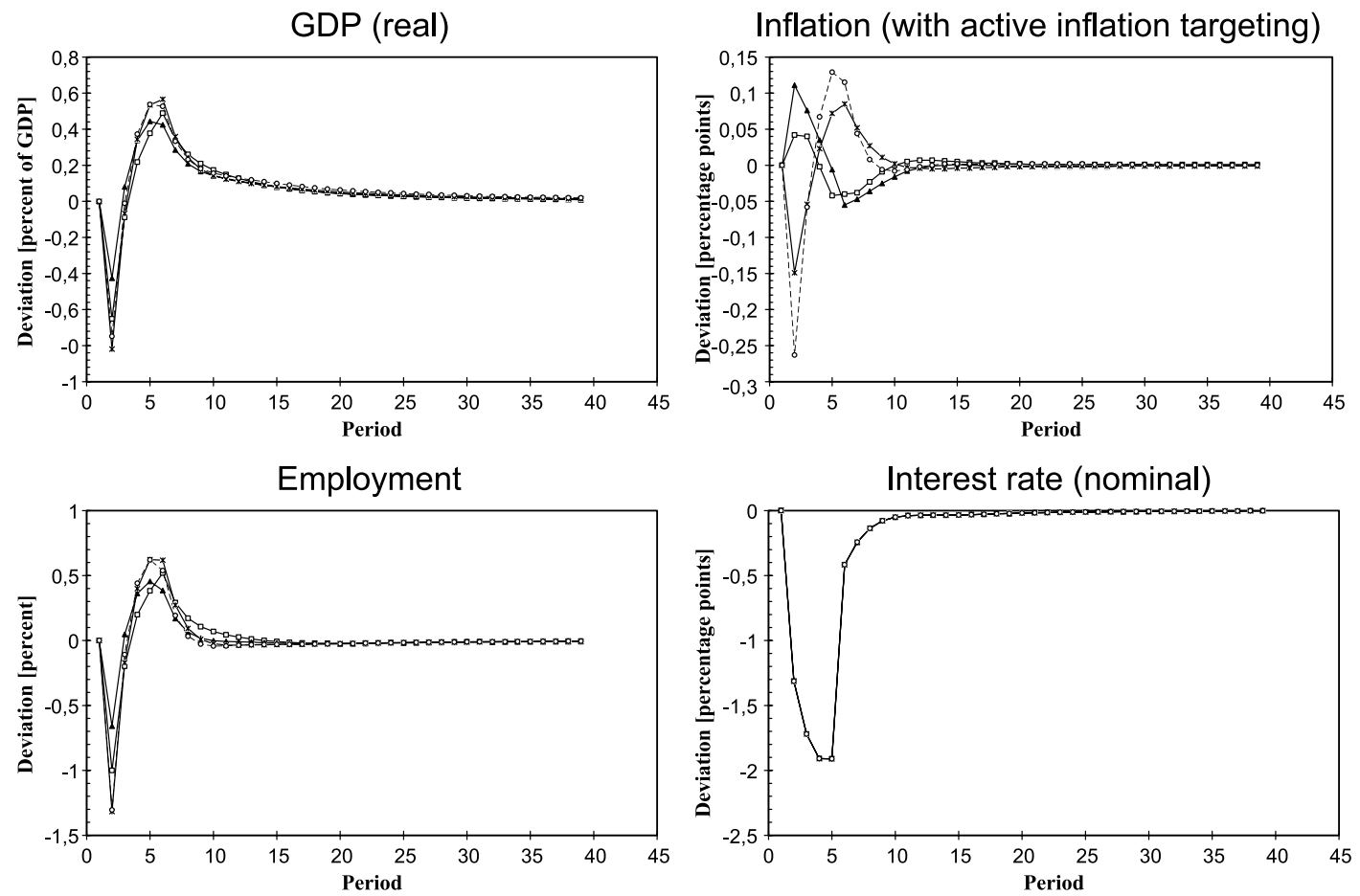

Fiscal deficit

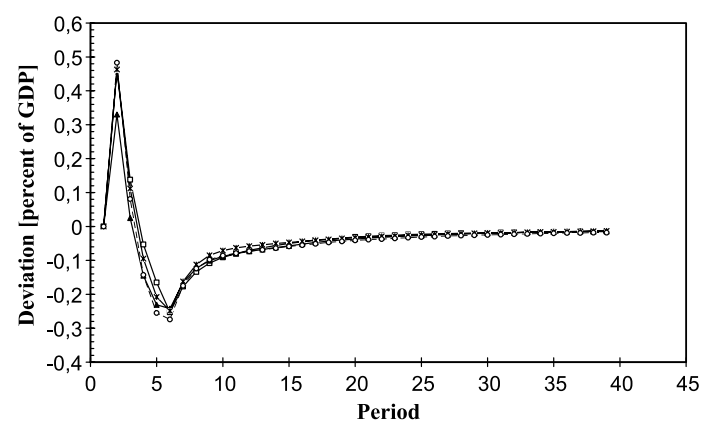

FIGURE 2. Temporary Negative Demand Shock. Germany: square; Austria: triangle; France: asterisk; Italy: circle. 
or less annihilates the negative demand shock very quickly; after three years, real GDP overshoots the baseline solution and returns soon, and inflation is near zero in all EA countries/regions. Also employment, after falling by less than 1.5 percent, returns to the baseline values after some overshooting within about 10 years. The fiscal deficit rises first, falls then due to lower interest payments and then returns to the baseline values gradually. The expansionary monetary policy reaction thus counteracts successfully the effects of the initial negative demand shock in this scenario. A negative global demand shock leads to an even more expansionary reaction of the ECB, which causes the nearextinction of the shock as in the case of the EA-only shock.

\section{Positive Supply and Demand Shocks}

The results of the corresponding temporary positive supply and demand shocks are identical to the results described above, with reversed signs. This is also true for the values of the objective functions (with only minor differences due to the asymmetric/ symmetric approach chosen).

\section{Fiscal Policies Diminishing the Public Sector (Fiscal Contractions)}

Next, we consider fiscal policies of the EA countries/regions aiming at diminishing the public sector permanently by reducing government expenditures by 1 percentage point of GDP. We assume, again, no active reaction of the non-EA countries/regions and the inflation targeting strategy of the ECB as before. First, we consider the isolated fiscal policy shock to capture the idea of fiscal policies starting in an intermediate position of the business cycle. Such a policy package can also be regarded as a permanent fiscal consolidation implemented by reductions in public expenditures. In particular, we assume a reduction of autonomous government expenditures by 0.25 percent of GDP in the first period, followed by reductions of 0.5 percent, 0.75 percent, and 1 percent of GDP (as compared to baseline values) subsequently. The 1 percent of GDP reduction of public expenditures is maintained for all remaining periods. The results of this scenario are shown in Figure 3.

In the short run, real GDP in the EA countries/regions drops by about 0.2 to 0.4 percent, with Italy facing the largest effect and Germany and Austria the smallest. After six to eight periods, depending on the region under consideration, GDP returns to the model baseline and remains above afterwards. These positive effects tend to grow over time to about 0.3 percent of baseline GDP in the long run (i.e., until the end of the simulation). Fiscal deficits drop rather quickly and finally converge to values that are lower by more than 1 percent of GDP than baseline values. The additional deficit reduction beyond the initial policy shock is due to positive effects on tax revenues from higher output. Employment drops during the first periods (maximum less than 0.7 percent), but finally (after at most 10 periods) overshoots and converges to a long run path that is slightly above the baseline. Monetary policy of the ECB acts in a restrictive way during the first periods and in an expansionary way in the long run, driving interest rates first up by at most 0.8 percent and then permanently down to more than 0.3 percent below baseline values.

Thus the permanent fiscal contraction, accompanied by monetary inflation targeting, clearly shows negative effects on output and employment in the short-run, but positive effects in the long run. Also all components of real GDP are above their baseline paths in the long run. The main reason for these long-run effects is the accumulation of private wealth due to lower taxes. The entire result can be interpreted 

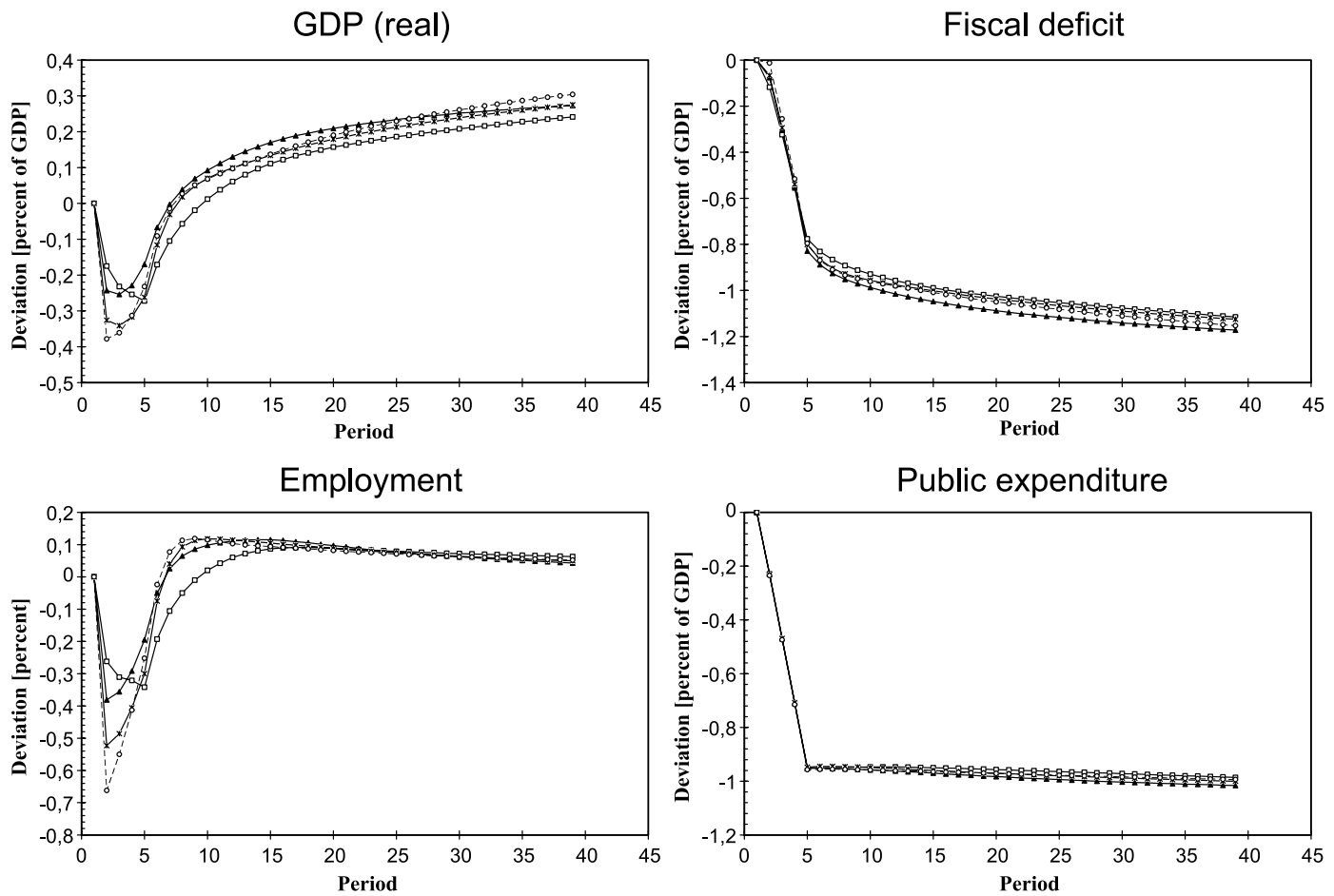

FIGURE 3. Permanent Fiscal Contraction. Germany: square; Austria: triangle; France: asterisk; Italy: circle.

as a case of Keynesian effects at the beginning of the fiscal contraction and nonKeynesian (expansionary) effects of the fiscal contraction in the long run. For all EA countries, the total welfare effects (as measured by the asymmetric quadratic objective function described before) are positive (except for very high time preferences).

\section{Fiscal Contraction with Supply and Demand Shocks}

In reality, economies are subject to all kinds of shocks under various economic conditions, and an isolated reduction of public expenditures without other macroeconomic noise will be rarely observed. Consequently, we analyze the effects and the welfare implications of such a fiscal policy package in recession and in boom scenarios. We confine ourselves to the negative and positive supply and demand shocks previously described as examples for such conditions. In both cases, we assume that the ECB actively and successfully targets European inflation, as in the previous sections. Lack of space precludes a more detailed presentation of the results, which can, however, be made available to interested readers.

\section{Negative Supply Shock and Fiscal Contraction}

Consider first the combination of the temporary negative supply shock to the EA countries/regions and the fiscal policy contraction shock. According to traditional (Keynesian) policy prescriptions, such a combination should be avoided in any case as it combines the negative effects of both shocks on output and employment. In the context 
of the MSG3 model, however, this is only true for the short run, where the negative supply shock effects are (slightly) reinforced by the fiscal contraction. In the long run, however, the model economies react in the same way as under the isolated permanent fiscal contraction shock: Real GDP rises above baseline by 0.2 percent, employment by 0.05 percent, interest rates below baseline by 0.3 percent. During the adjustment, employment and the fiscal deficit return faster to (and cross) the baseline path than under the isolated negative temporary supply shock, hence, this scenario is not even dominated by an inactive (rule-based) fiscal policy and is still less dominated by a Keynesian expansionary fiscal policy. For details, see Figure 4. All of these short-run and long-run effects of a permanent fiscal contraction occur also under a global temporary negative supply shock, where they are quantitatively larger than under the EA-only shock.

\section{Positive Supply Shock and Fiscal Contraction}

The combination of the positive supply shock (both global and EA-wide) with the fiscal policy contraction does not just mirror the previous cases as the short-run effects on output and employment counteract each other here. This results in a very favorable outcome, as can be seen in Figure 5: Real GDP rises initially by nearly 2 percent above baseline in spite of the fiscal contraction, the fiscal deficit falls quickly by more than 1 percent of GDP, employment rises initially by up to 1.5 percent of its baseline value, interest rates fall by about 1.5 percent. The long-run effects are qualitatively the same as before and quantitatively still more favorable.
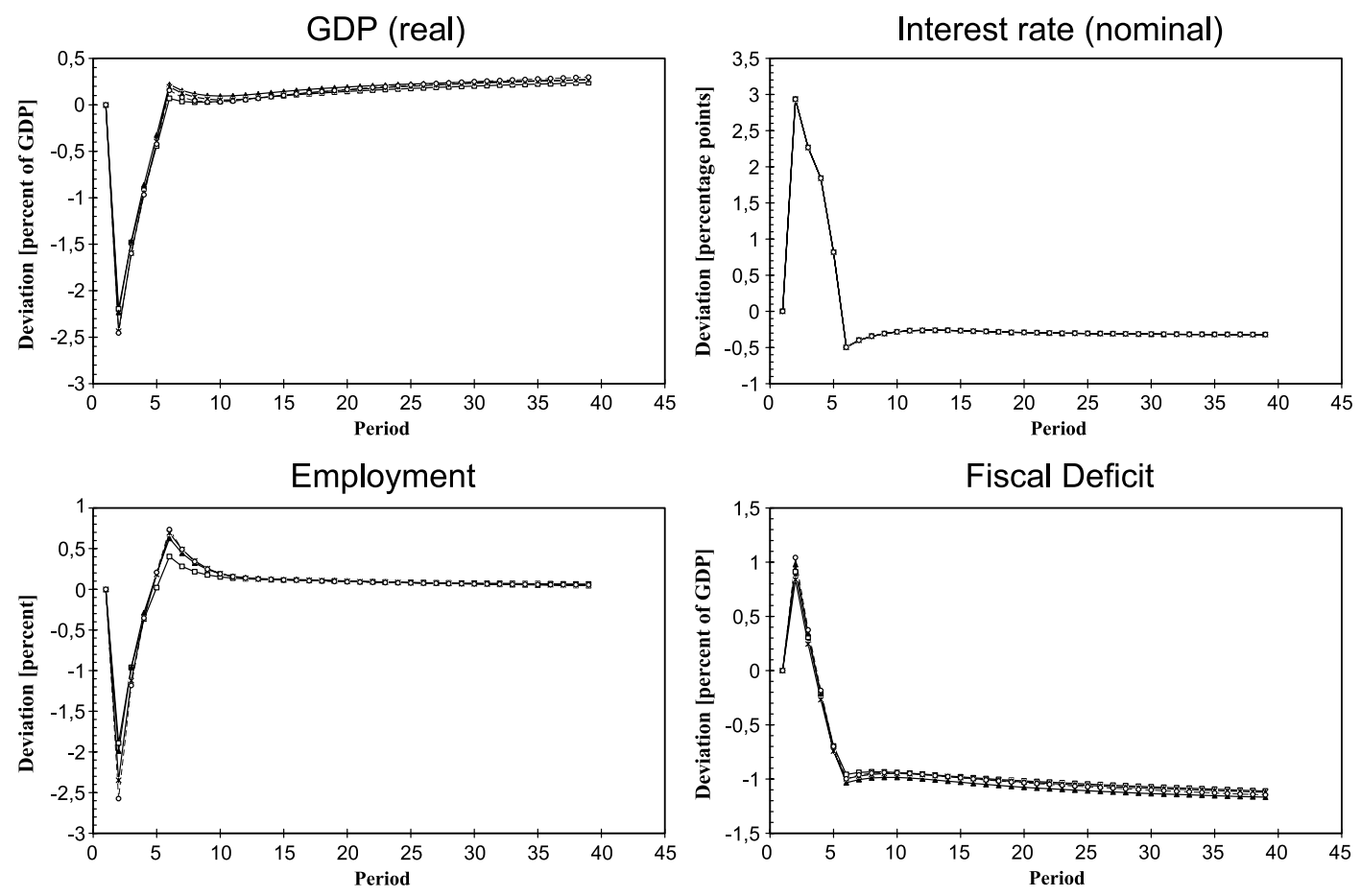

FIGURE 4. Negative Supply Shock and Permanent Fiscal Contraction. Germany: square; Austria: triangle; France: asterisk; Italy: circle. 

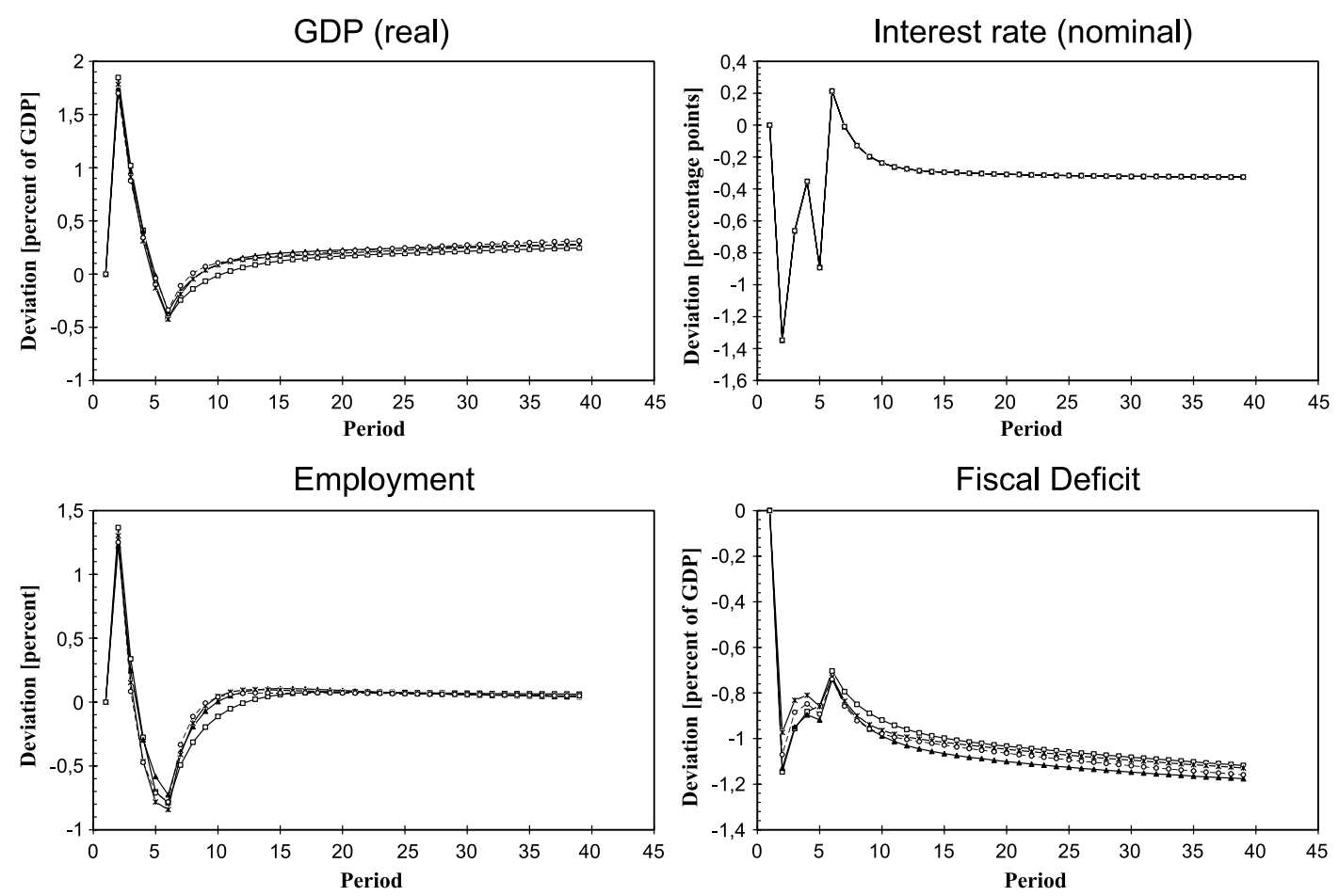

FIGURE 5. Positive Supply Shock and Permanent Fiscal Contraction. Germany: square; Austria: triangle; France: asterisk; Italy: circle.

Negative Demand Shock and Fiscal Contraction

As was shown above, in the case of a temporary negative demand shock, monetary policy aimed at inflation targeting acts in an expansionary way and counteracts the adverse effects on output and employment very effectively even without an active fiscal policy. This is also true for the short-run effects of a combined global temporary negative demand and permanent fiscal policy contraction shock, which shows the relative weakness of Keynesian short-run effects of fiscal policy in the MSG3 model for that case. Now real GDP and labor demand fall only by less than 1 percent and move quickly to their long-run paths, which are again above their respective baseline paths by 0.25 and 0.05 percent, respectively. Monetary policy is even more expansionary than in the scenario without fiscal contraction, resulting in a short-run decline of EA interest rates by 4 percentage points. The fiscal deficit falls by 1.4 percent of GDP in the short run and by 1.2 percent of GDP in the long run.

As in the scenario with the isolated temporary EA negative demand shock, monetary policy reacts in a less expansionary way under the EA than under the global shock when combined with a permanent fiscal policy contraction shock. This results in fairly adverse short-run effects in the EA shock scenario, with real GDP falling by 1.5 percent and employment even by more than 2 percent, in spite of an interest rate nearly 3 percentage points below its baseline value. Thus, an expenditure-based fiscal consolidation or a fiscal policy package designed to reduce the size of the public sector should not be started during a period of deficient-demand within Europe. On the other hand, worldwide deficient demand is less harmful when combined with a sufficiently expansionary 
(though inflation targeting) monetary policy of the ECB and no policy reaction outside the EMU. The long-run effects of the scenario under consideration are again the same as in the isolated fiscal contraction case.

\section{Positive Demand Shock and Fiscal Contraction}

Finally, the results of combinations of temporary positive demand shocks with permanent fiscal policy contractions shall be sketched. If the temporary shock is global, affecting all countries/regions of the model, and policy-makers outside the EMU do not react, an inflation-targeting ECB will nearly undo the shock. This means a very restrictive monetary policy, which raises interest rates by more than 5 percentage points, leading to real GDP and employment reductions by about more than 1 percent in the short run. This is an example of a scenario where a contractionary fiscal policy starting in a boom situation affects output and employment in a more adverse way than if starting in a recession. Of course, this result depends upon the assumptions of strict inflation targeting by the ECB and strict absence of active policies outside of the EMU, which may not be a very realistic scenario.

A more realistic and more favorable result is obtained from combining an EA-wide positive demand shock with the fiscal contraction and the monetary inflation targeting policies. In this case, real GDP and employment oscillate between about 1 and -1 percent relative to their baseline values in the short run. Monetary policy of the ECB is again restrictive though less than under the global shock. The long-run effects are again (as always) dominated by the permanent fiscal policy change.

\section{Welfare Effects of Fiscal Contractions}

Another interesting aspect of the fiscal policy contraction scenarios in normal, recession and boom environments is a comparison of their welfare effects. Table 3 gives an overview of welfare effects of some of the previously described simulation exercises for all EA countries/regions of the MSG3 model, both separately and as a total. We show only some results from European supply and demand shocks. Again, more detailed results are available upon request.

As expected, the temporary negative supply shock gives high welfare losses due to the output and employment decreases, which are amplified by inflation targeting ECB policies. The negative demand shock causes much smaller welfare losses due to the monetary expansion, which keeps output and employment near their baseline values.

TABLE 3

Some Welfare Effects

\begin{tabular}{lccccc}
\hline \hline & $\begin{array}{c}\text { Negative } \\
\text { supply } \\
\text { shock }\end{array}$ & $\begin{array}{c}\text { Negative } \\
\text { demand } \\
\text { shock }\end{array}$ & $\begin{array}{c}\text { Fiscal } \\
\text { contraction }\end{array}$ & $\begin{array}{c}\text { Fiscal contraction } \\
\text { and negative } \\
\text { supply shock }\end{array}$ & $\begin{array}{c}\text { Fiscal contraction } \\
\text { and positive } \\
\text { supply shock }\end{array}$ \\
\hline Germany & -2.24 & -0.16 & 1.30 & -1.53 & 3.13 \\
Austria & -2.16 & 0.06 & 1.50 & -1.37 & 3.21 \\
Italy & -2.49 & -0.25 & 1.20 & -2.62 & 2.94 \\
France & -2.32 & -0.26 & 1.26 & -2.17 & 2.87 \\
Rest of EA & -1.78 & -0.16 & 1.20 & -1.10 & 2.66 \\
Total & -10.99 & -0.76 & 6.46 & -8.79 & 14.81 \\
\hline
\end{tabular}

[Positive figures denote welfare gains, negative figures welfare losses]. 
The fiscal contraction scenario without any other shock produces welfare gains, which can be traced back to the non-Keynesian positive effects on GDP in the long run. For both fiscal contraction scenarios with supply shocks (the negative and the positive one), we find that the welfare effects of the recession and the boom scenarios are improved by the consolidation: For the negative supply shock by 2.2 'welfare loss units' (from -10.99 to -8.79 ), for the positive supply shock by 3.82 (from 10.99 to 14.81 ), both of which may be compared to the 6.46 of the pure fiscal contraction scenario. This shows the dominance of the fiscal contraction strategy, both in recessions and in boom periods, although its welfare-increasing effect is strongest when started in an intermediate position of the business cycle. Although the advantages of the fiscal contraction are higher in the absence of other shocks and in the presence of a positive supply shock, it is still true that the fiscal policy aimed at diminishing the public sector need not reduce economic welfare, even if applied during a recession. If these results can be confirmed in a more general context, they can be interpreted as an indication against weakening the essence of the Stability and Growth Pact, namely the requirement of obtaining a balanced budget or a budgetary surplus over the business cycle, preferably by reducing government expenditures.

\section{Conclusions}

In this paper, we have investigated how the European economies react to a fiscal policy aimed at diminishing the size of the public sector. Within the framework of the MSG3 model, a dynamic general equilibrium model of the world economy, we conducted several experiments to explore the effects of such a policy of reducing government expenditures permanently in different phases of the business cycle. To do so, we combined the fiscal contraction with negative and positive, global and EA-wide supply and demand shocks, assuming inflation targeting by the ECB. It turns out that negative Keynesian effects on output and employment tend to be mostly weak and short-lived, whereas non-Keynesian wealth effects lead to favorable long-run results of a policy of diminishing the public sector. Due to these long-run effects on output and employment, the fiscal contraction strategy enhances welfare as measured by an asymmetric quadratic objective function. The size of these welfare effects depends on the initial situation in a non-trivial manner.

The results of this paper depend on the assumptions made about the welfare or objective function, fiscal and monetary policy absence outside EMU, the ECB's monetary policy, the quantitative amount and the time pattern of the shocks, and-last not least - on the model used. All of these assumptions have to be relaxed or changed in a sensitivity analysis to investigate the robustness of the results reported here. Moreover, similar simulations should be performed with alternative macroeconomic models, in particular with more Keynesian ones, to check also for the robustness of the qualitative long-run result of welfare-augmenting fiscal contractions.

\section{References}

Allsopp, Christopher; Artis, Michael J. (eds.). "EMU, Four Years On," Oxford Review of Economic Policy, 19, 1, 2003.

Allsopp, Christopher; Vines, David (eds.). "Macroeconomic Policy after EMU," Oxford Review of Economic Policy, 14, 3, 1998.

Buti, Marco; Sapir, André. Economic Policy in EMU, Oxford: Clarendon, 1998. 
Buti, Marco; Sapir, André (eds.). EMU and Economic Policy in Europe, Cheltenham: Edward Elgar, 2003.

De Grauwe, Paul. Economics of Monetary Union, 5th ed., Oxford: Oxford University Press, 2003.

Eijffinger, Sylvester C. W.; de Haan, Jakob. European Monetary and Fiscal Policy, Oxford: Oxford University Press, 2000.

Hughes Hallett, Andrew; Mooslechner, Peter (eds.). "Challenges for Economic Policy Coordination within European Monetary Union,” Empirica, 26, 3, 1999.

McKibbin, Warwick J.; Sachs, Jeffrey D. Global Linkages, Washington, Brookings Institution, 1991.

McKibbin, Warwick J.; Wilcoxen, Peter J. "The Theoretical and Empirical Structure of the GCubed Model," Economic Modelling, 16, 1998, pp. 123-48.

Neck, Reinhard (ed.). "The Macroeconomics of EMU”, Open Economies Review, 13, 4, 2002.

Neck, Reinhard; Holzmann, Robert (eds.). "European Monetary and Fiscal Policies: Myths and Facts," Empirica, 29, 3, 2002. 